Psychology of Language and Communication 2014, Vol. 18, No. 2

\title{
DEVELOPING TEMPORAL SYSTEMS
}

\begin{abstract}
This paper reviews a body of research that reveals how children acquire the capacity to express the temporal location of episodes that they remember and those they anticipate for the future. The paper shows how the child's knowledge of language structure provides a window on the conceptual development of memory processes and the capacity for conceptual time travel away from the conversational context of the speech act.

Key words: temporal systems, event time, reference time, episodic memory, episodic future thinking, tense, aspect, deictic adverbs
\end{abstract}

\section{Introduction}

This paper investigates the development of the child's capacity to talk about the experiences that she/he remembers from the past and experiences that he/ she can anticipate in the future. Temporal systems constitute one component of the child's knowledge of language providing the capacity to talk about the temporal contour of events. These enable the child to express conceptual time travel into the past and onto the future, and in doing so, they provide a window on conceptual development. In order to understand how the linguistic systems develop, it is important to coordinate research findings on conceptual development with the data on language acquisition. The development of temporal systems represents a conversational imperative, as children must come to understand and express the location of events in time relative to referents such as speech time. The pattern of acquisition depends on the relationship between the way the child processes linguistic information and the way the target language structures

Address for correspondence: Richard M. Weist, Department of Psychology, State University of New York at Fredonia, 32 Rosalyn Court, Fredonia, NY 14063, USA. E-mail: weist@fredonia.edu 
temporal contours making cross-linguistic comparisons imperative. This paper focuses on the acquisition of child Polish with comparisons to child English. The paper begins with an overview of temporal systems theory and some critical properties of infant-toddler conceptual development. According to this theory, there is a developmental sequence beginning with the "Event-time (ET) System" and expanding into the "Reference-time (RT) System". This investigation of the ET to RT sequence progresses from a description of relatively early research to more recent studies on the acquisition of tense, grammatical aspect, and lexical aspect. The next three sections concern the emergence of the RT system and the transition from the ET to the RT system. Finally, the research on language acquisition is related to mechanisms of acquisition and conceptual development.

\section{Temporal systems theory}

A temporal system is an instantiation of the child's knowledge of how their native language structures the temporal dimension. Within this framework, development involves the gradual integration of three concepts: 1) speech time, the interval of the speech act, 2) event time, the interval of the event in focus in the utterance (i.e., the primary event), and 3) reference time, the temporal context established for the event in focus. Even before there is linguistic evidence for a temporal system, children are known to talk about events that are remote in time and space (i.e., the "non-here-and-now"), e.g., Melissa Bowerman's (1981) daughter Christy at 1;5 said "write Sissy" claiming that the child Sissy had put marks on her hand, at 1;5 Christy states an intended plan saying ride, and then she got her teddy bear, put it in a movable chair, and spun the chair, and at 1;9, Christy said "/ ə sipi wa /" (slippery water) when walking past a puddle where she had fallen the day before. Bowerman (1981) emphasized that these utterances were spontaneous (i.e., not prompted or "scaffolded"). In these examples, Christy has not yet engaged the syntactic structure of English to code past reference. Weist (1986) referred to this early phase in development as the "Speech Time (ST) System" since the child has not yet begun to code a departure from the time of the speech act. Depending on the specific language, children will acquire some type of tense-aspect-modality rule system, and they will begin to code temporal contours, e.g., at 2;0 - 2;2, Christy said, "I cried", "She barks", and "You will watch me in the bathroom"(Bowerman, 1981). Thus, by two years of age, Christy placed activities (i.e., crying and watching) prior and subsequent to speech time, and she expressed the concept of a timeless activity. Weist (1986) referred to this phase in development as the "Event Time (ET) System". Minimally, children locate the primary event in the sentence relative to the deictic center of the speech act. Depending on the language, they may also express aspectual concepts such as completed and/or modal concepts such as direct versus indirect knowledge of an event (e.g., Turkish does both). Smith 
(1980) and Weist (1986) argued that reference time is limited to speech time at this phase of development. An important innovation in the child's temporal system occurs when she/he can establish remote intervals of temporal reference, and this innovation was referred to as the "Reference Time (RT) System". Among other indicators of the RT system, children begin to utilize adverbial clauses to locate reference time, e.g., at 3;0, Matty said "Yeah but when trying to catch daddy, daddy put me under the water" and at 2;6 Emily said, "When I'm done playing, I can have my sucker" (see Weist \& Zevenbergen, 2008). Hence, this paper investigates how the ET and the RT systems develop in child language and evaluates the cognitive implications.

\section{Infant-toddler cognitive development}

If the infant-toddler could not think about events that are removed from the here-and-now, we would not expect them to utilize a linguistic code to express such remote locations. If, in fact, young children were conceptually limited in this manner, we might interpret Christy's (2;0) utterances, "I cried" or "I didn't fall down, Emily did", as some kind of imitation rather than the application of a past tense rule within a larger linguistic system. During the early research on temporal reference, this Piaget inspired view of cognitive development was prevalent (e.g., Piaget, 1954). In contrast to the Piagetian theoretical era, it is quite clear today that the infant-toddler is not so conceptually limited. The research indicates that infants utilize "core knowledge systems" to process information. According to Elizabeth Spelke (2000, p. 1233), core knowledge systems "are mechanisms for representing and reasoning about particular kinds of ecologically important entities and events." Considerable research has been carried out on the object representational system by Renée Baillargeon as well as Spelke (e.g., 1991 review), for example, Lou and Baillargeon's (2005) studies of the changes in the infant's knowledge of object interactions between $2 \frac{1}{2}$ and $3 \frac{1}{2}$ months. The important point here is that infants have the capacity to construct representations. The research on infant memory processes demonstrates that they can not only construct representations, they can remember them. Carolyn Rovee-Collier (e.g., 1997) showed how recognition memory develops during the period from 2 to 12 months of age, e.g., a combination of methods revealed a two week retention interval for 6-month-old children. In another line of research (e.g., Bauer, 1996), toddlers between the ages of about one and two years of age revealed the capacity to imitate a sequence of events after lengthening retention intervals (i.e., expanding differed imitation). This means that prior to entering the initial period of language acquisition, the infant-toddler has the capacity to construct and retrieve representations of objects and events (i.e., declarative memory capacity). Returning to utterances such as Christy's "I cried" and "I didn't fall down" at 2;0, we have considerable scientific reason to suppose that she is telling her mother 
about episodes in her life, and she has engaged the structure of her language to do so. Furthermore, Christy's thinking includes future episodes as well as past, e.g., at (2;2) "I going put them in a box so them won't fall down" and "Daddy will get up and Daddy will hold my little doll" (Bowerman, 1981).

In one of his influential analyses of memory processes, Tulving (e.g., 1985) contrasted two kinds of declarative memory; "semantic" and "episodic". Semantic memory concerns general knowledge such as the knowledge about concepts, e.g., birds have wings. Episodic memory involves unique events in one's life having time and space referents, e.g., a trip to the zoo. Bauer (2007, p. 354) referred to this kind of memory as "auto-biographical" memory adding the property of reexperiencing the episode. In their investigation of episodic memory, Peterson \& Rideout (1998) interviewed children about trips to the emergency room. The age at the time of the accident was 13 to 34 months. The children were interviewed shortly after their accident and then after $6,12,18, \& 24$ months. The younger toddlers (e.g., 1;6) were unable to recall anything about their experience. The older toddlers (e.g., 1;10) were able to provide partial reports, and the 2-year-olds could give partial (e.g., 2;2) or full (e.g., 2;10) reports of their experience even after 24 months. The authors concluded that the "younger toddlers" could not report on the accident because they did not have the linguistic capacity to code the events at that time. By 2-years-old, the children remembered where, when, and how the episode happened, i.e., they demonstrated "episodic" memory.

\section{The emerging Event Time (ET) system: Early research}

Depending on the language, the ET system may include some combination of tense, aspect, and / or modality. In their study of the acquisition of Polish, Weist, Wysocka, Witkowska-Stadnik, Buczowska, and Konieczna (1984) focused on the interaction of tense, grammatical aspect, and lexical aspect. The research combined a naturalistic-longitudinal research design with an experimental-crosssectional design. Within the longitudinal design, six children (ages 1;7-2;2) were recorded in caregiver-child interactions, and some of this data is available in the CHILDES archives (see MacWhinney, 2000). There was an overall interaction of tense and aspect with the following high frequency categories: 1) past and future tense with perfective grammatical aspect and telic lexical aspect, and 2) present tense with imperfective grammatical aspect and atelic lexical aspect. While the structure of tense-aspect systems varies cross-linguistically, when children locate event time prior to speech time, the semantic structure of the predicate is likely to be telic, and when event time is located at speech time, the predicate is likely to be atelic (e.g., Aksu-Koç, 1988 for Turkish, Antinucci \& Miller, 1976 for Italian, Bar-Shalom, 2002, for Russian, and Shirai, 1993 for Japanese). Probing the data beyond the overall frequency counts, the more interesting / important findings were revealed. While the children were more likely to talk about prior 
events having an inherent terminal point, they were not limited in this regard. The children also made past tense reference to prior activities, e.g., Kasia $(2 ; 0)$, bawita się '(she) played / was playing' and Kubuś $(2 ; 1)$, czytatem o Soczewce '(I) read / was reading about Soczewka'. This finding is important as it shows that children can remember experiences that are independent of the here-and-now context of speech time, and they can utilize the relevant tense-aspect morphology. Furthermore, if the children could only use a particular verb with a unique tense-aspect morpheme, it might be argued that these are "verb-island" constructions which do not reveal the acquisition of a linguistic rule system (Tomasello, 2003). However, the children contrasted imperfective with perfective past, e.g., Marta $(1 ; 7$ - 1;9), wkladata / wtożyta, '(She) was putting in / (She) put in', and imperfective with perfective future, e.g., Kasia $(2 ; 0$ - 2;3), będę rysowała / narysuję '(I) will be drawing / (I) will draw'. Further, the children contrasted imperfective present with perfective future, e.g., Wawrzon $(2 ; 2-2 ; 5)$ idzie / pójdę '(he/she) is walking / (I) will walk'. The fact that the children produced aspect and tense contrasts within the same verb supports the argument that they have begun the process of acquiring the linguistic rule system for coding temporal contours. Regarding the implication of the future tense utterances, the children might be expressing speech time intentions (a modal meaning) or they may be anticipating an experience subsequent to speech time (a deictic meaning). If their future forms were truly deictic, this would provide additional evidence for conceptual time travel away from the here-and-now (see Weist, Pawlak, \& Carapella, 2004 and Weist, in press).

In the experimental-cross-sectional research design, there were two groups of nine children with average ages of $2 ; 6$ and $3 ; 6$. The children were presented with a tense-aspect elicitation task that focused on past and future temporal reference. In the past reference problems, the experimenter acted out a sequence of two events with toys describing the action in present tense, and then she asked the child to tell 'what happened first'. The elicitation question was formed in the imperfective past tense providing the obligatory context for a past tense reply and presenting an imperfective bias, i.e., co $X$ robit / robiła najpierw?. The first event in the sequence for half of the problems was an activity, e.g., running, and in the other half, the initial event involved a change of states, e.g., breaking a stick. Hence, the situation was either atelic or telic in nature. In the future reference problems, the experimenter acted out a sequence of events that anticipated an additional event. Once again, present tense was used to describe the ongoing action. For the future reference problems, the elicitation question was formed in the perfective future, i.e., co sie stanie? 'what will happen?'. The perfective aspect in the elicitation question conveys the idea that the event sequence will be completed. The mean percentage of past and future tense responses for the two groups of children was as follows: 1) $2 \frac{1}{2}$ years, $92 \%$ past and $66 \%$ future, and 2) $3 \frac{1}{2}$ years, $99 \%$ past and $83 \%$ future. The children were just as or even 
more likely to elicit a past tense description of the initial event when it was an activity as contrasted with a change of states indicating that the product of a change of states in the speech act context (e.g., a broken stick) is not required for the past reference. The future reference problems involved an anticipated event. The future tense responses indicate that young children can think about and express an anticipated event. Regarding future reference, the findings of this experiment were recently supported with a very different procedure and $31 / 2$-year-old children acquiring English (Atance \& O'Neil, 2005). Expanding on Tulving's concept of episodic memory, Atance (2008, p. 99) introduced the concept of "episodic future thinking" to involve pre-experiencing an event. In summary, in a Slavic language like Polish, by about two years of age, the tense and aspect components of the ET system have been integrated and are utilized to express past and future reference. They provide at least some evidence for the capacity to re-experience and pre-experience episodes.

\section{The emerging Event Time (ET) system: Recent research}

Weist et al. (2004) investigated the syntactic-semantic interface in the acquisition of predicate / verb morphology in six children learning English and six children learning Polish utilizing data found in the CHILDES archives. The children were followed from their earliest recorded caregiver-child interaction to the age 4;11 or their last transcript. The methodology was designed to reveal the "history" of the development of the tense-aspect morphology for a set of predicates for each child. In order to implement this methodology, we utilized the framework of Role and Reference Grammar (RRG) to define predicate structure (see Van Valin, 2005). This enables the systematic identification of telic and atelic predicates and provides an understanding of how these predicates are realized in the verbs of the child's vocabulary. For example, the verb, to eat, is derived from an atelic predicate structure in the sentence, He's eating peanuts (Abe, 2;5), and the same verb has a telic component within its predicate structure in the sentence, I'm eating a peanut butter sandwich (Abe, 2;7). The specific set of predicates that were identified was unique for each child. For the children acquiring English there were 10 in each child's set and for Polish there were 12 . The following examples of telic and atelic predicates were frequently found in both languages: 1) telic, spad-a-ć / spas-ć 'to fall' and psu-ć / po-, ze$p s u$-ć 'to break' and 2) atelic, ptaka-ć / po-, roz-plaka-ć 'to cry' and bawi-ć się / po-bawi-ć się 'to play'. The following three variables were analyzed: 1) the age of the emergence of tense-aspect forms, 2) the likelihood of the emergence of tense-aspect forms, and 3) the age of the acquisition of tense-aspect contrasts. Both languages have past, present, and future tense. Polish has perfective and imperfective aspect where perfective is the marked form specifying the concept "completion". English has non-progressive and progressive aspect where 
Table 1 . The average age of the emergence of tense-aspect forms for (atelic / telic) predicates

\begin{tabular}{ccc}
\hline Polish & Aspect \\
\hline Tense & Perfective & Imperfective \\
\hline Past & $3 ; 4 / \mathbf{2 ; 2}$ & $2 ; 7 / \mathbf{3 ; 1}$ \\
Non-past (Present) & Non-existent & $2 ; 1 / \mathbf{2 ; 8}$ \\
Non-past (Future) & $2 ; 9 / \mathbf{2 ; 3}$ & $*\{2 ; 5 / \mathbf{3 ; 0}\}$ \\
\hline
\end{tabular}

* The future imperfective data was scored but could not be compared to English.

\begin{tabular}{ccc}
\hline English & \multicolumn{2}{c}{ Aspect } \\
\hline Tense & Non-progressive & Progressive \\
\hline Past & $2 ; 11 / 2 ; 7$ & $3 ; 2 / 3 ; 5$ \\
Non-past (Present) & Excluded & $2 ; 10 / 2 ; \mathbf{1 0} *\{2 ; 4 / 2 ; 7\}$ \\
Non-past (Future) & $2 ; 11 / 2 ; 8$ & Not Observed \\
\hline
\end{tabular}

* 'Present' progressive forms were scored with and \{without\} the auxiliary.

progressive is the marked form coding the notion "on-going". Table 1 contains the average age of the emergence of the target morphology for both languages (see also Weist et al., 2004, Table 7a, p. 47). Each entry in the table represents a sum over the 10 / 12 predicates in each child's data set and over the six children in a language making it a robust finding.

In both languages, telic predicates emerge relatively early in the perfective and the non-progressive aspectual forms in past and future tenses (i.e., 2;2 and 2;3 for Polish and 2;7 and 2;8 for English). In both languages, atelic predicates emerge relatively early in the imperfective and the progressive forms in the present tense (i.e., 2;1 for Polish and 2;10 for English). In English, verb forms with the progressive inflection (-ing) but without the "present" auxiliary are found relatively early (i.e., 2;4) and verb forms with the progressive inflection and with the past form of the auxiliary (was / were) are relatively late (i.e., 3;2). We argued that English past progressive is acquired relatively late as it involves an internal perspective on episodes occurring prior to speech time, i.e., a transfer of reference time away from speech time. Since the form "present tense and perfective aspect" does not occur in Polish, the related present non-progressive (or simple present) was excluded from the analysis. During the period from about 2 to 5-years-old, children acquiring English do not produce future progressive verb forms, i.e., they are absent. The likelihood findings show the mirror image of the age findings since early acquisitions are quite likely to be found and later acquisi- 
tions less likely. In general, contrasts in tense (i.e., Polish, 2;4 \& English 3;0) were found earlier than contrasts in aspect (i.e., Polish, 2;11 \& English 3;5). In order to contrast in tense, the same predicate was likely to be found in past and future tense holding aspect constant, e.g. past and future perfective / non-progressive. However, to realize an aspectual contrast, a predicate with its inherent semantic structure (i.e. telic or atelic) must be observed in contrasting grammatical aspect, e.g., past perfective versus past imperfective. This will be somewhat late in both languages because of the interaction of lexical and grammatical aspect. In summary, the acquisition of the morpho-syntactic structure interacts with semantic structure from the beginning of the acquisition process. Hence, an adequate theory of language acquisition will have to specify a fundamental semanticsyntactic interface explaining the relationship between predicate structure and clause structure (e.g., RRG, VanValin, 2005). Returning to the properties of the ET system, the predicate tracking research clearly shows the early development of tense contrasts. Children express deictic relations as they locate episodes into the past and onto the future.

\section{The emerging Reference Time (RT) system}

When children are about 3-years-old, they begin to express relatively complex relations between speech time, event time, and reference time. About one year earlier, at 2-years-old, they expressed deictic relations between speech time and event time as well as aspectual and modal contrasts. Approximately one year later, an innovation in temporal reference is observed as reference time becomes integrated into a more complex system. At this phase of development, children demonstrate the capacity to establish reference time at a remote location (i.e., away from speech time), and then, they relate the primary event in the utterance to the reference time interval. In order to capture this developmental process, Pawlak, Oehlrich, and Weist (2006) investigated the naturalistic observations of six children acquiring English and six children acquiring Polish in the age range from 1;6 to 5;0 (i.e., the same children who participated in Weist et al., 2004). The 2004 study focused on the ET system, and the 2006 study was focused on the emergence of the RT system.

Pawlak et al. (2006) traced the emergence of the seven terms shown in Table 2, and she derived the following two dependent measures: 1) the age on the initial correct occurrence of each target term (see Table 2), and 2) the age on the initial correct occurrence of three contrasting temporal constructions as follows: a) when / jak versus then / potem, b) before / przed versus after / po, and c) any two of the three deictic adverbs. Summing across the target terms for the 6 children acquiring one of the languages, the average age of the initial correct occurrence was 2;11 for English and 2;10 for Polish. On the average, the children acquiring both languages produced the target contrasts at 3;0. Comparing the data from 
Table 2. The mean age of the initial correct occurrence of 7 target terms in English and Polish

\begin{tabular}{lccccccc}
\hline \multicolumn{7}{c}{ English } \\
\hline Terms & when & then & before & after & yesterday & today & tomorrow \\
Age & $3 ; 1$ & $2 ; 10$ & $3 ; 2$ & $3 ; 2$ & $3 ; 3$ & $2 ; 11$ & $2 ; 10$ \\
\hline \multicolumn{7}{c}{ Polish } \\
\hline Terms & jak & potem & przed & po & wczoraj & dzisiaj & jutro \\
Age & $2 ; 8$ & $2 ; 8$ & $3 ; 3$ & $3 ; 0$ & $2 ; 11$ & $2 ; 3$ & $2 ; 11$ \\
\hline
\end{tabular}

the Weist et al. (2004) study with the Pawlak et al. (2006) study, children begin to acquire the ET system at about 2-years-old, and that developmental process is still unfolding when the evidence for the RT system emerges at 3-years-old.

\section{ET to RT system transition: Adverbs}

Weist and Buczowska (1987) observed how temporal adverbs were used in the conversational contexts of three children acquiring Polish during the period from $2 ; 4$ to $3 ; 2$. The research focused on deictic adverbs within the following three sets: 1) immediate, just prior-to, during, or subsequent to speech time, 2) cyclic, one daily cycle prior-to, at, or subsequent-to speech time, and 3) remote, sometime in the past or future. Table 3 shows the age of the initial occurrence of the target adverbs within the corpora of at least one of the three children. The adverbs in the "immediate" set were found in the earliest recordings of the caregiver-child interactions, and it is likely that they would have been detected in these children at a younger age. The adverbs juz 'already', teraz 'now', and zaraz 'soon' not only emerge at an early age (i.e., $2 ; 4-2 ; 5)$; they also emerge with deictic tense-adverb coordination, e.g., już with past tense. In the predicate tracking study (Weist et al., 2004), the acquisition past, present and future tense forms was estimated at 2;2, 2;1, and 2;3 respectively which is consistent with and supportive for the tense-adverb findings. The fact that the adverbs in the immediate set emerge in a deictically coordinated manner supports the claim that the tense morphology in the ET system has deictic meaning resembling the target language. Furthermore, for sentences involving the "immediate" adverbs, reference time remains at speech time (i.e., within the domain of the ET system). The onset of these tense-adverb constructions does not yet constitute a transition into the RT system.

In their analysis of the "cyclic" set of adverbs, Weist and Buczowska (1987) and Pawlak et al. (2006) both found that children produce tense-adverb deictic incongruities during acquisition. Table 3 contains the initial observations of the 
Table 3. The initial occurrence of the temporal adverbs in three sets of adverbs

\begin{tabular}{cccccc}
\hline \multicolumn{2}{c}{ Immediate } & \multicolumn{2}{c}{ Cyclic $^{*}$} & \multicolumn{2}{c}{ Remote } \\
\hline Adverb & Age & Adverb & Age & Adverb & Age \\
\hline $\begin{array}{c}j u \dot{z} \\
\text { 'already' }\end{array}$ & $2 ; 4$ & $\begin{array}{c}\text { wczoraj } \\
\text { 'yesterday' }\end{array}$ & $2 ; 7$ & $\begin{array}{c}\text { dawno } \\
\text { 'long ago' }\end{array}$ & $2 ; 9$ \\
$\begin{array}{c}\text { teraz } \\
\text { 'now' }\end{array}$ & $2 ; 4$ & $\begin{array}{c}\text { dzisiaj } \\
\text { 'today' }\end{array}$ & $2 ; 5$ & $\begin{array}{c}\text { kiedyś } \\
\text { 'in the past' }\end{array}$ & $2 ; 11$ \\
$\begin{array}{c}\text { zaraz } \\
\text { soon' }\end{array}$ & $2 ; 5$ & $\begin{array}{c}\text { jutro } \\
\text { 'tomóniej } \\
\text { 'later' }\end{array}$ & $2 ; 9$ \\
\hline
\end{tabular}

* The initial occurrence of these adverbs always involved a tense-adverb deictic contradiction.

cyclic adverbs taken from the Weist and Buczowska study, and the age values in Table 2 represent the initial correct occurrence of the cyclic adverbs (i.e., tense - reference day coordinated) taken from the Pawlak et al. (2006) study. Together, these studies demonstrate that it takes the children a few months to acquire the meaning of the cyclic adverbs. As the children attempt to establish reference time at a location away from speech time, they make errors. There were at least two kinds of errors. In one type, tense points in one direction and the adverb in another direction, e.g., Wawrzon (2;8) Jutro bawi-t-e-m tymi zabawkami, 'Tomorrow I played with these toys'. In Wawrzon's sentence, the verb bawić 'to play' is inflected for past tense (-t-), but the adverb points to the future. In the second type of example, the child's meaning for the adverb does not match the adult's meaning, e.g., Wawrzon (2;9) Wczoraj by-t-e-m Łódź, 'Yesterday I was in Łódź'. In fact, Wawrzon had visited this Polish city, but it was some time ago and not the previous day. The past tense form (- $t-)$ of the verb być 'to be' is deictically consistent with the adverb, but the meaning is different, and not cyclic. At this age, Wawrzon is establishing reference time away from speech time, and he is relating event time to reference time. However, he still has to learn the meaning of the cyclic adverbs. As the children approach 3-years-old, they produce adverbs from the "remote" set, and these were found to be used correctly, e.g., Wawrzon $(2 ; 11)$ Kiedyś $i$ to się zepsu-t-o wtaśnie, 'And some time ago, it just broke (by itself)'.

\section{ET to RT system: Re- / pre-experiencing episodes}

Weist and Zevenbergen (2008) investigated temporal reference in 10 children acquiring English in the age range from approximately 2 to 5 years of age. The study focused on past time reference, but there were some comparative observa- 
tions of non-past reference. The purpose of the research was to discover evidence for conceptual time travel. In other words, how can we tell from the child's language that the child has re- / pre-experienced an episode? Three primary forms were analyzed as follows: 1) simple past, 2) past progressive and 3) sentences with an adverbial clause having the subordinate conjunction, when, and past temporal reference, i.e., "past when-sentences". In order to establish a reasonable level of productivity, successive transcripts were analyzed, and the acquisition criterion was "five target forms". For the 10 children, the average age of acquisition was as follows: 1) simple past 2;4,2) past progressive 2;10, and 3) past when-sentences $3 ; 6$. There was a 6 to 8 month interval between the acquisitions of these forms. While these estimates of acquisition are more precocious than the predicate tracking estimates found in Table 1 for English, the delay from simple past to past progressive is similar. Further, the acquisition timing for the simple past falls within estimates for the ET system, and emergence of "past when-sentences" fits the acquisition estimates for the RT system. Within the framework of the ET / RT temporal systems theory, simple past forms were judged to have deictic value relating speech time to event time, but having reference time limited to speech time. Sentences with temporal adverbial clauses such as "past when-sentences" were seen as prototypical examples of the establishment of reference time away from speech time. Further, it can be argued that past-progressive forms require an internal perspective on the prior episode. Hence, the use of past progressive would be predicted in the transition from the ET to RT system. Since past progressive is a periphrastic form requiring an auxiliary that caries agreement as well as tense information, we also observed the acquisition of present progressive for a comparison. The acquisition of present progressive was estimated at 2;5 which is only one month after simple past but five months before past progressive. Thus, the timing of the emergence of past progressive does not reduce to the morpho-syntactic requirements.

The second analysis was designed to evaluate memory processes. We were interested in evidence that might inform us that the child has moved his/her conceptual frame of reference away from speech time to the time-space coordinates of the remembered experience, i.e., evidence for re-experiencing the episode. To this end, the following three dependent measures were derived within the conversational context: 1) reference time is established by the child or the interlocutor, 2) a supporting event is mentioned in the discourse segment, and 3) the primary event must refer to a real world and self-relevant event. The mean number of discourse segments having these three criteria and the number of children who produced at least one such example was as follows for the three forms of temporal reference: 1) simple past, 1.2 and 4 of 10,2) past progressive, 2.2 and 9 of 10, and 3) past when-sentences, 3.4 and 10 of 10. During the period of development from about 2 to 4 years of age, there is linguistic evidence that children are making the transition from an ET system to an RT system. Information from 
the conversational context reveals that they are gradually gaining the capacity for conceptual time travel into the past. Weist and Zevenbergen (2008) provided some limited evidence for future reference and potential pre-experiencing episodes by analyzing "non-past when-sentences". Non-past when-sentences were acquired at 3;4 and used for future or timeless reference with some evidence for pre-experiencing an episode (see also Weist, in press).

\section{Early childhood conceptual development}

The research concerning the development of memory processes during infancy and toddlerhood has shown that the acquisition of language plays an important role. As language becomes available to the toddler, it provides a linguistic code to the representations of the child's experiences, and this process facilitates episodic memory (e.g., Peterson \& Rideout, 1998; Simcock \& Hayne, 2003). During this period of development when children are about 2 years of age and the ET system is taking shape, children are now using the morpho-syntax of their native language to talk about episodes they remember and ones they anticipate in the future.

During the same period of development, the concept of "self" is emerging (see the review by Howe, Courage, \& Edison, 2003). At 18 months, infants show "mark directed behavior" in the mirror self-recognition task as they touch their nose following unobtrusive marking. At 22-24 months, they provide verbal labels for the mark on their nose. Between the ages of 2 and 3 years, they begin to succeed on delayed self-recognition tasks that involve viewing a video of a marking experience and showing an understanding of the so called "temporally extended self". The concept of self-knowing is part of the definition of episodic memory, and the concept of self-relevance is emphasized in Bauer's (2007) definition of autobiographical memory. Consistent with this emphasis on the self-concept, Howe et al. (2003) argued that, "the emergence of the cognitive self late in the second year of life that launches autobiographical memory and the coincident developments in both language and social cognition that occur in the same time frame do not directly affect its onset" (pp. 472-473). One important development in language during this period is the acquisition of the RT system where children specify the time-space coordinates of the remembered episodes. Thus, according to Mark Howe's assessment, the linguistic capacity to freely establish reference time, i.e., specify the temporal context for to-be-remembered episodes, will not influence the development of autobiographical memory. However, Weist and Zevenbergen (2008) found that evidence for the RT system co-varies with evidence that children "re-experience" episodes, and the notion of re-experiencing is one hallmark of autobiographical memory. The research on the structure of recounting prior experiences and research on telling stories in early childhood has also linked language to autobiographical memory. From their extensive research 
on children's capacity to recount their experiences, Fivush, Haden, and Adam (1995) proposed, "For memories to become part of the life story, they must be organized as coherent narratives" (p. 35). One important source of coherence is the establishment of temporal structure found in the emergence of the ET and RT systems. Hence, the research supports the argument that the development of temporal systems facilitates the development of autobiographical memory.

\section{Acquiring temporal systems}

What are the mechanisms that underlie the acquisition process? In this paper, I will only highlight two of the most prominent alternatives, show where they are inadequate, and suggest one potentially promising alternative. The two prominent theories are Principles and Parameters theory (or innate structure based theory), e.g., Meisel (1994) and Sano and Hyams (1994), and Usage-Based theory, e.g., Tomasello (2003). Regarding the functional morphology of temporal systems, Meisel (1994, p. 94) proposed that, "the emergence of these categories and rules is an autonomous process" which doesn't rely on sematic principles. In fact, the course of development within the ET system is guided by the principles of the semantic structure of predicates (e.g., see Table 1 above). Assuming an innate structure based model, Sano and Hyams (1994) predicted that "... children prefer an analysis of -ed as a perfective aspect marker rather than a past tense marker ..." (p. 551), but there is no such preference. Tense-aspect morphology is crucially acquired together, and if a "preference" existed, it might go to tense (e.g., see Table 4). The mechanisms for acquisition were claimed to be autonomous innate principles and parameters (see Meisel, 1995), and the child language data does not support the predictions of this theory.

According to Tomasello's (2000) usage-based process, children acquire "an inventory of item-based schemas" (p. 70), and "before their third birthdays children use individual verbs and syntactic constructions in just the way they have heard and understood them being used - with only very limited abilities to go beyond what they have heard" (p. 71). The item-based schemas include verb-island constructions which are made up of a verb with a frozen morpheme plus slot(s) to be filled with nouns, e.g., [slot crying]. However, neither temporal nor agreement morphology is frozen within so called "verb-islands" during this phase of development (Weist et al., 2004, \& Weist, 2009). The predicate tracking research, reviewed in Table 1, has shown that children acquiring Polish and English have produced practically the full range of tense-aspect forms before they are 3-yearsold. In order to demonstrate level of productivity / creativity that defines the child's ET system, Weist et al., (2004) also evaluated contrast presented here in Table 4. Table 4 presents the average age of the emergence of the following contrasts: 1) tense, i.e., two different tense values with aspect held constant (e.g., perfective past versus perfective future), 2) aspect, i.e., two different values of 
Table 4. The average age of the emergence of tense-aspect, tense, and aspect contrasts

\begin{tabular}{lccc}
\hline Language & Tense-aspect & Tense & Aspect \\
\hline Polish & $2 ; 10$ & $2 ; 4$ & $2 ; 11$ \\
English & $3 ; 0$ & $3 ; 0$ & $3 ; 5$ \\
\hline
\end{tabular}

aspect with tense constant (e.g., past perfective versus past imperfective), and 3) tense-aspect, any contrast involving different values of tense and aspect (e.g., past perfective versus present imperfective). In contrast to a list of "verb-island" constructions obtained by "culture learning" (i.e., imitation + understanding), children have acquired the morpho-syntactic structure of a tense-aspect rule system. Yet, the question remains, how do they acquire the ET system?

In some sense, Meisel and Tomasello are both correct in that children are innately predisposed for language, and they need to develop in a communicative environment for the acquisition process to unfold. An adequate theory of innate principles will be based on the interaction of syntactic with semantic and pragmatic principles (e.g., Van Valin, 2005), and the principles of "usage" will involve a theory of information processing (e.g., Slobin's, 1985 "operating principles"). According to Slobin's (2001, p. 441) idea of "typological bootstrapping", the course of language acquisition will depend on the relationship between the way in which the target language is structured and the way in which the child processes information, i.e., the child's "operating principles". According to the argument, the following four properties of language structure should facilitate the acquisition process during the development of the ET system: 1) obligatory coding, 2) main verb affixing (or "local coding"), 3) one morpheme codes one semantic concept (i.e., 1-to-1 coding), and 4) consistent application (e.g., agreement marked across tenses). The structure of the Polish temporal system more clearly meets these specifications than English, and Polish children acquire the system significantly more rapidly. Hence, crosslinguistic comparisons provide a valuable tool for determining how children process the linguistic evidence in their culture, and how they abstract the morpho-syntactic rules from this evidence.

\section{Concluding remarks}

Regarding temporal reference, the research that was reviewed in this paper makes the case that there are two phases in development described as the event time (ET) and reference time (RT) systems. Initially and very early (before 2-yearsold in Polish), children make reference to past and future events with utterances void of the tense-aspect morphology. Since there is no linguistic evidence for 
deictic coding, Weist (1986) referred to this as the speech time (ST) system. Here, there is conversational evidence for thinking outside the domain of the "hereand-now" of the speech act but no linguistic evidence. Between the ages of 2-and 3-years-old, it is clear that children can utilize the morpho-syntactic structure of their language for temporal reference, and this period was referred to as the ET-system. During this phase in development, children express the temporal location of their episodic memories relative to speech time. The linguistic code facilitates retention. However, we have argued that reference time is limited to speech time, i.e., the deictic center of the conversation, and the data supports this argument. This constraint on reference time begins to change rapidly, and by 3 years of age, there is mounting evidence for varied locations of reference time revealing the RT-system. This innovation in the child's temporal system supports the cohesive structure of memories, and memories with this structure are likely to be remembered beyond early childhood.

\section{References}

Aksu-Koç, A. (1998). The role of input vs. universal predispositions in the emergence of the tense-aspect morphology: Evidence from Turkish. First Language, $18,255-280$.

Antinucci, F. \& Miller, R. (1976). How children talk about what happened. fournal of Child Language, 3, 167-189.

Atance, C.M. (2008). From the past into the future: the developmental origins and trajectory of episodic future thinking. In E. Dere, A. Easton, L. Nadel, \& J.P. Huston (Eds.), Handbook of Episodic Memory (pp. 99-114). Netherlands: Elsevier.

Atance, C.M. \& O'Neill, D.K. (2005). The emergence of episodic future thinking in humans. Learning and Motivation, 36, 126-144.

Bar-Shalom, E. (2002). Tense and aspect in early child Russian. Language Acquisition, 10 (4), 321-337.

Bauer, P.J. (1996). What do infants recall of their lives? American Psychologist, 51 (1), 29-41.

Bauer, P.J. (2007). Remembering the Times in our Lives: Memory in Infancy and Beyond. Mahwah, NJ: Lawrence Erlbaum Associates.

Bowerman, M. (1981). Notes for the Nijmegen Workshop. Nijmegen: MPI.

Fivush, R., Haden, C., \& Adams, S. (1995). Structure and coherence of the preschoolers' personal narratives over time: Implications for childhood amnesia. fournal of Experimental Child Psychology, 60, 32-56.

Howe, M.L., Courage, M.L., \& Edison, S.C. (2003). When autobiographical memory begins. Developmental Review, 23, 471-494.

Lou, Y. \& Baillargeon, R. (2005). When the ordinary seems unexpected: evidence for incremental physical knowledge in young infants. Cognition, 95, 297-328. 
MacWhinney, B. (2000). The CHILDES Project: Tools for Analyzing Talk (3 $3^{\text {rd }}$ ed.). Mahwah, NJ: Lawrence Erlbaum Associates.

Meisel, J.M. (1994). Getting FAT: Finiteness, agreement, and tense in early grammars. In J.M. Meisel (Ed.), Bilingual First Language Acquisition: French and German Grammatical Development (pp. 89-129). Amsterdam: John Benjamins.

Meisel, J.M. (1995). Parameters in acquisition. In P. Fletcher \& B. MacWhinney (Eds.). The Handbook of Child Language (pp. 10-35). Cambridge, MA: Blackwell.

Pawlak, A., Oehlrich, J.S., \& Weist, R.M. (2006). Reference time in child English and Polish. First Language, 26, 281-298.

Peterson, C. \& Rideout, R. (1998). Memory for medical emergencies experienced by 1- and 2-year-olds. Developmental Psychology, 14, 1059-1072.

Piaget, J. (1954). The Construction of Reality in the Child. New York: Basic Books. Rovee-Collier, C.K. (1997). Dissociations in infant memory: Rethinking the development of implicit and explicit memory. Psychological Review, 104, 467-498.

Sano, T. \& Hyams, N. 1994. Agreement, finiteness, and the development of null arguments. In M. Gonzàlez (Ed.), NELS 24: Proceedings of the North East Linguistic Society (pp. 543-558). Amherst, MA: GLSA.

Shirai, Y. (1993). Inherent aspect and the acquisition of tense-aspect morphology in Japanese. In H. Nakajima \& Y. Otsu (Eds.), Argument Structure: Its Syntax and Acquisition (pp. 185-211). Tokyo: Kaitiakusha.

Simcock, G. \& Hayne, H. (2002). Breaking the barrier? Children fail to translate their preverbal memories into language. Psychological Science, 13, 225-231.

Smith, C. (1980). The acquisition of time talk: relations between child and adult grammars. Journal of Child Language, 7, 263-278.

Spelke, E S. (1991). Physical knowledge in infancy: Reflections on Piaget's theory. In S. Carey \& R. Gelman (Eds.), The Epigenesis of mind: Essays on Biology and Cognition (pp. 133-170). Hillsdale, NJ: Lawrence Erlbaum Ass.

Spelke, E.S. (2000). Core knowledge. American Psychologist, 55, 1233-1243.

Slobin, D.I. (1985). Crosslinguistic evidence for the language making capacity. In D. Slobin (Ed.), The Crosslinguistic Study of Language Acquisition. Vol. 2 (pp. 1157-1249). Hillsdale, NJ: Lawrence Erlbaum.

Slobin, D.I. (2001). Form/function relations: How do children find out what they are? In M. Bowerman \& S. Levinson (Eds.), Language Acquisition and Conceptual Development (pp. 406- 409). Cambridge: Cambridge University Press.

Tomasello, M. (2000). First steps toward a usage-based theory of language acquisition. Cognitive Linguistics, 11, 61-82.

Tomasello, M. (2003). Constructing a Language: A Usage-Based Theory of Language Acquisition. Cambridge, MA: Harvard University Press.

Tulving, E. (1985). How many memory systems are there? American Psychologist, 40, 385-378.

Van Valin, R.D. (2005). The Syntax-Semantics-Pragmatics Interface: An Introduction to Role and Reference Grammar. Cambridge: Cambridge University Press. 
Weist, R.M. (1986). Tense and aspect. In P. Fletcher \& M. Garman(Eds.), Language Acquisition (pp. 356-374). Cambridge: Cambridge University Press.

Weist, R.M. (2009). One-to-one mapping of temporal and spatial relations. In J. Guo, E. Lieven, N. Budwig, S. Ervin-Tripp, K. Nakamura, \& S. Özçalişkan (Eds.), Crosslinguistic Approaches to the Psychology of Language: Research in the Tradition of Dan Isaac Slobin (pp. 69-80). Hillsdale, NJ: Lawrence Erlbaum Ass. Weist, R.M. (in press). Future temporal reference in child language. In P. De Brabanter, M. Kissine, \& S. Sharifzadeh (Eds.), Future Times: Future Tenses (pp. 87-113). Oxford: Oxford University Press.

Weist, R.M. \& Buczowska, E. (1987). The emergence of temporal adverbs in child Polish. First Language, 7, 217-229.

Weist, R.M., Pawlak, A., \& Carapella, J. (2004). Syntactic-semantic interface in the acquisition of verb morphology. Fournal of Child Language, 31, 31-60.

Weist, R.M., Pawlak, A., \& Hoffman, K. (2009). Finiteness systems and lexical aspect in child Polish and English. Linguistics, 47 (6), 1321-1350.

Weist, R.M., Wysocka, H., Witkowska-Stadnik, K., Buczowska, E., \& Konieczna, E. (1984). The defective tense hypothesis: On the emergence of tense and aspect in child Polish. Fournal of Child Language, 11, 347-374.

Weist, R.M. \& Zevenbergen, A. (2008). Autobiographical memory and past time reference. Language Learning and Development, 4 (4), 291-308. 